Document downloaded from:

http://hdl.handle.net/10251/36552

This paper must be cited as:

Molina Puerto, J.; Fernández Sáez, J.; Del Río García, Al.; Bonastre Cano, JA.; Cases Iborra, FJ. (2013). Chemical and electrochemical study of fabrics coated with reduced graphene oxide. Applied Surface Science. 279:46-54. doi:10.1016/j.apsusc.2013.04.020.

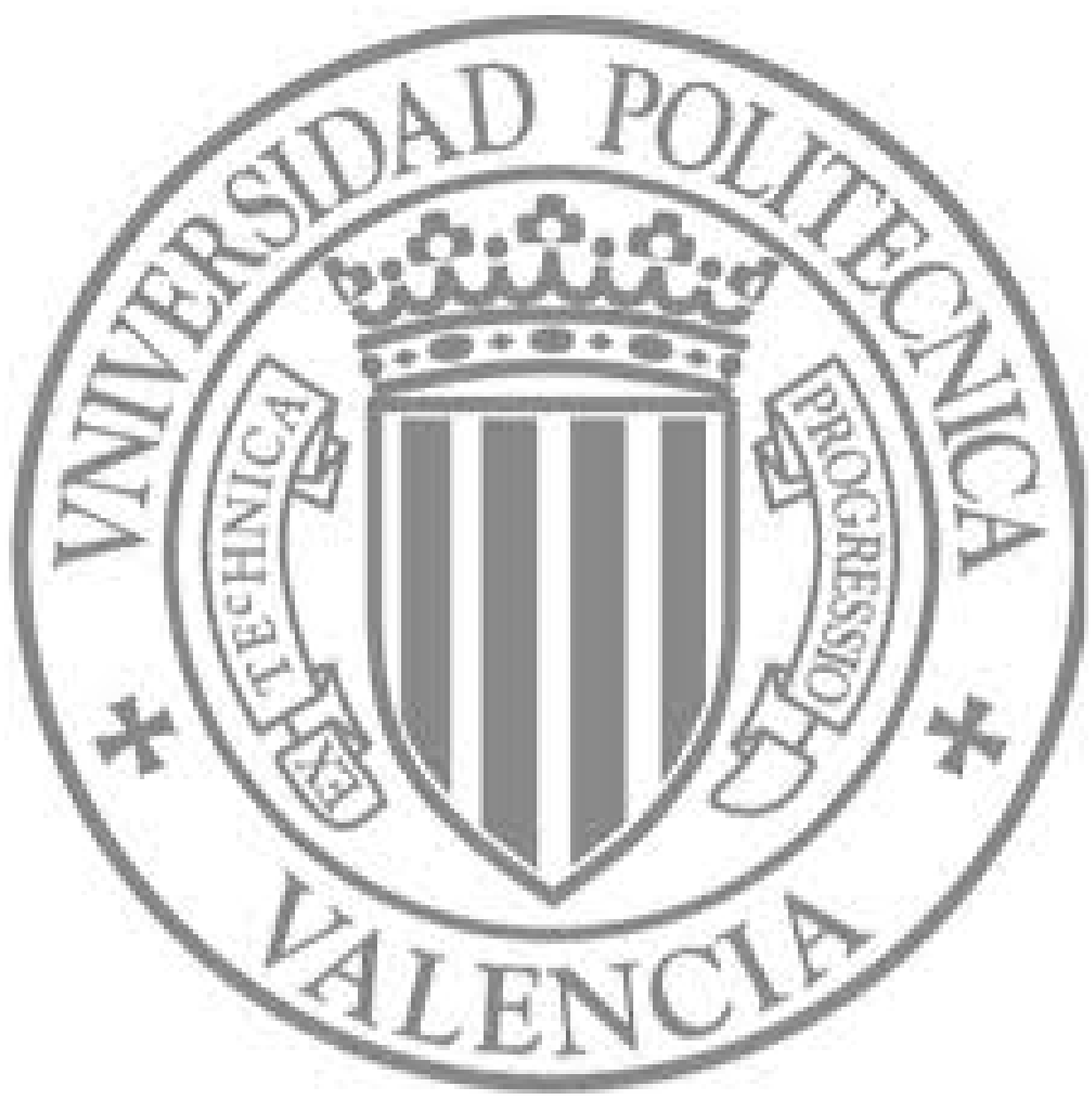

The final publication is available at

http://dx.doi.org/10.1016/j.apsusc.2013.04.020

Copyright Elsevier 


\section{Accepted Manuscript}

Title: Chemical and electrochemical study of fabrics coated with reduced graphene oxide

Author: J. Molina J. Fernández A.I. del Río J. Bonastre F. Cases

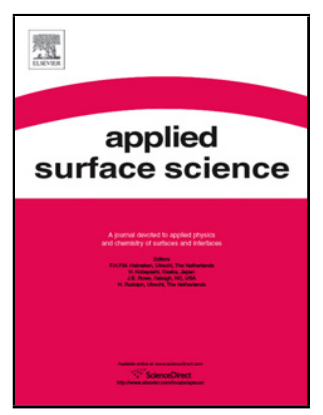

PII: S0169-4332(13)00709-5

DOI: http://dx.doi.org/doi:10.1016/j.apsusc.2013.04.020

Reference: APSUSC 25488

To appear in:

APSUSC

Received date: $12-12-2012$

Revised date: 25-3-2013

Accepted date: $1-4-2013$

Please cite this article as: J. Molina, Chemical and electrochemical study of fabrics coated with reduced graphene oxide, Applied Surface Science (2013), http://dx.doi.org/10.1016/j.apsusc.2013.04.020

This is a PDF file of an unedited manuscript that has been accepted for publication. As a service to our customers we are providing this early version of the manuscript. The manuscript will undergo copyediting, typesetting, and review of the resulting proof before it is published in its final form. Please note that during the production process errors may be discovered which could affect the content, and all legal disclaimers that apply to the journal pertain. 


\title{
Chemical and electrochemical study of fabrics coated with reduced graphene oxide
}

\author{
J. Molina, J. Fernández, A.I. del Río, J. Bonastre, F. Cases* \\ Departamento de Ingeniería Textil y Papelera, EPS de Alcoy, Universitat Politècnica \\ de València, Plaza Ferrándiz y Carbonell s/n, 03801 Alcoy, Spain
}

\begin{abstract}
Polyester fabrics coated with reduced graphene oxide (RGO) have been obtained and later characterized by means of chemical and electrochemical techniques. X-ray photoelectron spectroscopy showed a decrease of the oxygen content as well as an increase of the $\mathrm{sp}^{2}$ fraction after chemical reduction of graphene oxide (GO). The electrical conductivity was measured by electrochemical impedance spectroscopy (EIS) and showed a decrease of 5 orders of magnitude in the resistance $(\Omega)$ when GO was reduced to RGO. The phase angle also changed from $90^{\circ}$ for PES-GO (capacitative behavior) to $0^{\circ}$ for $\mathrm{RGO}$ coated fabrics (resistive behavior). In general an increase in the number of RGO layers produced an increase of the conductivity of the fabrics. EIS measurements in metal/sample/electrolyte configuration showed better electrocatalytic properties and faster diffusion rate for RGO specimens. Scanning electrochemical microscopy was employed to test the electroactivity of the different fabrics obtained. The sample coated with GO was not conductive since negative feedback was obtained. When GO was reduced to RGO the sample behaved like a conducting material since positive feedback was obtained. Approach curves indicated that the redox mediator had influence on the electrochemical response. The $\mathrm{Fe}(\mathrm{CN})_{6}{ }^{3-/ 4-}$ redox mediator produced a higher electrochemical response than $\mathrm{Ru}\left(\mathrm{NH}_{3}\right)_{6}{ }^{3+/ 2+}$ one.
\end{abstract}


Keywords: conducting fabrics, graphene, graphene oxide, polyester, scanning electrochemical microscopy, electrochemical impedance spectroscopy.

* Corresponding author. Fax.: +34 966528438; telephone: +34 966528412. E-mail addresses: fjcases@txp.upv.es (Prof. F. Cases).

Authors e-mail addresses: jamopue@doctor.upv.es (Dr. J. Molina), jfernandezmuro@hotmail.com (J. Fernández), delgaran@doctor.upv.es (Dr. A.I. del Río), joboca@txp.upv.es (Dr. J. Bonastre).

\section{Introduction}

The production of fabrics with new properties such as thermal regulation [1], flame resistant [2], self-cleaning [3], electrical properties [4], etc., has attracted great attention during the last years. Among these properties the electrical conduction has attracted particular attention. Different methods have been employed to provide the fabrics with electrical conductivity. For example the use of metallic fibers inserted in the fabric, chemical metallization of fibers [5], the extrusion of fibers with conductive particles such as carbon derivatives [6] or the synthesis of conducting polymer films on the fabrics [7-9].

On the other hand, the discovery of graphene and its derivatives has opened a new era in the field of physics and materials science. The amazing electronic, mechanical, optical or thermal properties properties shown by this material open the door to a range of different applications [10-17]. Different methods have been employed for the production of graphene and its derivatives [16-18]. The first method reported by 
Novoselov et al. [10] was the mechanical exfoliation from graphite that produced high quality graphene sheets. However, the quantity of graphene obtained was minimal, reason why other methods such as chemical vapor deposition or chemical methods were developed. Among them, the chemical methods have been proposed as an alternative for the production of larger quantities of graphene. One of these methods is the production of graphene oxide (GO) by the oxidation of graphite. However, GO is electrically insulating, reason why it has to be reduced afterwards by chemicals to produce reduced graphene oxide (RGO) [18]. RGO is electrically conducting due to the restored $\mathrm{sp}^{2}$ bonds networks. Graphene derivatives have also been found of interest to produce composite conducting materials $[19,20]$ with such low filler content as $0.1 \%$ [19].

Fabric materials have the advantage of possessing a high surface area as well as a good flexibility and mechanical properties, what makes them interesting supports to deposit other materials. Regarding conducting fabrics coated with graphene and its derivatives very little has been reported [21-23]. Yu et al. deposited graphene directly on the fabrics and later electrodeposited $\mathrm{MnO}_{2}$ to produce supercapacitors [21]. Other strategy employed is to adsorb graphene oxide $(\mathrm{GO})$ sheets on the surface of the fabric and later reduce them employing chemicals such as hydrosulfite [22] or hydrazine [23]. Graphene oxide sheets are adsorbed on the surface of the fabric due to the attraction forces existing between the functional groups of the fabrics and the oxidized groups of graphene oxide sheets. In the present paper the last strategy has been employed to produce reduced graphene oxide coated on polyester fabrics (which is the synthetic fiber most widely employed in textile industry).

Together with the synthesis of graphene coated fabrics, the electrochemical characterization of these materials is another field to be studied. In this paper we have employed two electrochemical techniques; electrochemical impedance spectroscopy 
(EIS) and scanning electrochemical microscopy (SECM), to characterize the RGO coated fabrics obtained. SECM is a powerful technique with several applications in different fields such as the study of metals corrosion [24], biological systems [25], etc. EIS has been shown also as a useful technique to characterize the electrical properties of conducting fabrics [26].

\section{Experimental}

\subsection{Reagents and materials}

All reagents employed were of analytical grade.

For the synthesis: Sodium dithionite $\left(\mathrm{Na}_{2} \mathrm{~S}_{2} \mathrm{O}_{4}\right)$ was acquired from Merck. Monolayer graphene oxide (GO) powders were acquired from Nanoinnova Technologies S.L. (Spain). Polyester fabrics were acquired from Viatex S.A. and their characteristics were: fabric surface density, $140 \mathrm{~g} \mathrm{~m}^{-2}$; warp threads per $\mathrm{cm}, 20$ (warp linear density, 167 dtex); weft threads per cm, 60 (weft linear density, 500 dtex). These are specific terms used in the field of textile industry and their meaning can be consulted in a textile glossary [27].

For the characterization: Sulphuric acid $\left(\mathrm{H}_{2} \mathrm{SO}_{4}\right)$ and potassium chloride $(\mathrm{KCl})$ were purchased from Merck. Hexaammineruthenium (III) chloride $\left(\mathrm{Ru}\left(\mathrm{NH}_{3}\right)_{6} \mathrm{Cl}_{3}\right) 98 \%$, $\mathrm{K}_{3} \mathrm{Fe}(\mathrm{CN})_{6} 99 \%$ and $\mathrm{K}_{4} \mathrm{Fe}(\mathrm{CN})_{6} 99 \%$ were used as received from Acrōs Organics.

When needed, solutions were deoxygenated by bubbling nitrogen $\left(\mathrm{N}_{2}\right.$ premier X50S). Ultrapure water was obtained from an Elix 3 Millipore-Milli-Q Advantage A10 system with a resistivity near to $18.2 \mathrm{M} \Omega \mathrm{cm}$.

2.2. Synthesis of reduced graphene oxide on polyester fabrics 
Polyester fabrics were coated with reduced graphene oxide (RGO) similarly to Fugetsu et al. [22]. GO solution was employed mixing GO monolayer powders in an ultrasound bath for $30 \mathrm{~min}$, solutions of $3 \mathrm{~g} \mathrm{~L}^{-1}$ of GO were obtained. The first stage of the synthesis was putting in contact the GO solution with the fabric to allow the adsorption of GO sheets on the surface of the fabrics, this stage lasted 30 minutes. After this time, fabrics with GO were dried during $24 \mathrm{~h}$ in ambient conditions. The second stage of the synthesis was the reduction of GO to RGO. Fabrics coated with GO were placed during $30 \mathrm{~min}$ in a solution containing the reducer $(0.5 \%$ weight of sodium dithionite at approximately $90^{\circ}$ ). This time was considered sufficient to achieve the conversion of GO to RGO as other studies have shown [22, 28]. After the adsorption and after reduction process, the samples were washed several times to remove graphene oxide and reduced graphene oxide sheets loosely attached to the fabrics. Samples with different number of RGO coatings $(1,2,3,4)$ were obtained (PES-1G, PES-2G, PES3G, PES-4G) repeating the procedure mentioned above. Samples coated with graphene oxide (PES-GO) were also obtained for comparison of the different results.

\subsection{Scanning electron microscopy (SEM)}

A Jeol JSM-6300 scanning electron microscope was employed to observe the morphology of the samples using an acceleration voltage of $10 \mathrm{kV}$. Samples were coated with Au employing a Sputter Coater Bal-Tec SCD 005.

\subsection{X-ray photoelectron spectroscopy measurements (XPS)}

XPS analyses were conducted at a base pressure of $5 \cdot 10^{-10}$ mbars and a temperature around $-100{ }^{\circ} \mathrm{C}$. XPS spectra were obtained with a VG-Microtech Multilab electron spectrometer by using unmonochromatized $\mathrm{Mg} \mathrm{K \alpha}(1253.6 \mathrm{eV})$ radiation from a twin 
anode source operating at $300 \mathrm{~W}(20 \mathrm{~mA}, 15 \mathrm{kV})$. The binding energy (BE) scale was calibrated with reference to the $\mathrm{C} 1 \mathrm{~s}$ line at $284.6 \mathrm{eV}$. C1s and $\mathrm{O} 1 \mathrm{~s}$ core levels XPS spectra were analyzed for the different fabrics (PES-GO, PES-1G, PES-2G, PES-3G, PES-4G).

\subsection{Electrochemical impedance spectroscopy measurements}

An Autolab PGSTAT302 potentiostat/galvanostat was employed to perform electrochemical impedance spectroscopy (EIS) analyses. EIS measurements were performed in the $10^{5}-10^{-2} \mathrm{~Hz}$ frequency range. The amplitude of the sinusoidal voltage was $\pm 10 \mathrm{mV}$. Measurements were carried out in two types of electrode configuration.

1) EIS analyses in a two-electrode arrangement were performed to evaluate the electrical properties of dry samples. A metal/sample/metal symmetrical configuration was employed placing a mercury drop on the different fabrics that were located on a stainless steel plate. The electric contact was done with a stainless steel rod contacting with the mercury drop, the other electric contact was made through the stainless steel plate.

2) A standard three-electrode design was employed to measure the EIS response of PES-GO and PES-RGO samples in $0.1 \mathrm{M} \mathrm{H}_{2} \mathrm{SO}_{4}$ solutions. An asymmetrical configuration metal/sample/electrolyte was employed. Sample was mounted on a stainless steel plate (employed to produce the electrical connection). An $\mathrm{Ag} / \mathrm{AgCl}(3 \mathrm{M} \mathrm{KCl})$ electrode and stainless steel rod were employed as reference electrode and counter electrode, respectively. The electrolyte resistance values were obtained replacing the textile working electrode by a stainless steel one for each different $\mathrm{pH}$ solution. 
The experimental results were also fitted using a non-linear least squares fitting minimisation method by ZView software (version 2.7).

\subsection{Scanning electrochemical microscopy (SECM)}

SECM measurements were carried out with a scanning electrochemical microscope of Sensolytics. A three-electrode configuration cell consisting of a $100-\mu \mathrm{m}$-diameter $\mathrm{Pt}$ ultra-microelectrode (UME), a Pt wire auxiliary electrode and an $\mathrm{Ag} / \mathrm{AgCl}(3 \mathrm{M} \mathrm{KCl})$ reference electrode. Solutions of $\mathrm{Ru}\left(\mathrm{NH}_{3}\right)_{6} \mathrm{Cl}_{3}, \mathrm{~K}_{3} \mathrm{Fe}(\mathrm{CN})_{6}$ and $\mathrm{K}_{4} \mathrm{Fe}(\mathrm{CN})_{6} 0.01 \mathrm{M}$ in 0.1 $\mathrm{M} \mathrm{KCl}$ (supporting electrolyte) were prepared. Thus, two types of redox mediators, $\mathrm{Ru}\left(\mathrm{NH}_{3}\right)_{6}{ }^{3+/ 2+}$ and $\mathrm{Fe}(\mathrm{CN})_{6}{ }^{3-/ 4-}$ were selected to see the influence of the redox mediator on the electrochemical responses obtained. All the experiments were carried out in inert nitrogen atmosphere. The substrates were samples $\left(0.5 \times 0.5 \mathrm{~cm}^{2}\right)$ cut from the different fabrics (PES, PES-GO, PES-1G, PES-2G, PES-3G, PES-4G). These samples were glued to microscope slides with epoxy resin. Approach curves were obtained by recording the tip current as the Pt UME tip was moved in z direction. Approach curves give us an indication of the electroactivity of the surface. These curves were compared to the theoretical ones (positive and negative feedback models).

In addition, the Pt UME tip electrode was positioned inside the influence of the electrochemical field, at a proper height over the substrate surface, to record the $2 \mathrm{D}$ and 3D constant-height SECM images. The substrate surfaces in all the measurements were at their open circuit potential (OCP).

\section{Results and discussion}

3.1. Scanning electron microscopy (SEM) 
Scanning electron microscopy (SEM) was employed to observe the morphology of the different fabrics. In general it is difficult to observe the RGO sheets by SEM. However, in this case they could be observed due to the wrinkling of its surface. Fig. 1-a,b show micrographs for the PES-1G sample. In Fig. 1-a a RGO sheet can be observed deposited on a fiber of polyester, the size of the RGO sheet is around $6 \times 6 \mu \mathrm{m}$. The sheet is wrinkled as it can be seen in this figure; this type of behavior has also been observed when depositing graphene derivatives on flat surfaces [19]. Fig. 1-b shows different RGO sheets deposited on a polyester fiber. When more layers of RGO were deposited the RGO content increased, but it was more difficult to observe the RGO sheets. Fig. 1c,d show micrographs of the PES-4G sample, where all the surface is completely coated with RGO.

\subsection{X-ray photoelectron spectroscopy measurements (XPS)}

$\mathrm{X}$-ray photoelectron spectroscopy was employed to characterize chemically the samples coated with GO and RGO. First of all, the PES substrate was also characterized to assign the different contributions to the $\mathrm{C} 1 \mathrm{~s}$ spectrum (figure not shown). Three deconvoluted peaks were obtained in the XPS spectrum corresponding to binding energies of 285.1, 286.3 and $289.1 \mathrm{eV}$. The first binding energy corresponds to C-C/C$\mathrm{H}$ groups in phenyl rings. The band at $286.3 \mathrm{eV}$ was ascribed to $\mathrm{C}-\mathrm{O}$ bonds $\left(\mathrm{O}-\mathrm{CH}_{2}\right)$ and the band at $289.1 \mathrm{eV}$ was attributed to $\mathrm{O}=\mathrm{C}-\mathrm{O}$ ester group [29]. All of these bands correspond to the polyester structure.

Fig. 2-a shows the high resolution C1s XPS spectrum for the PES-1G sample. Four peaks were deconvoluted at $284.4,285.9,287.0$ and $289.0 \mathrm{eV}$. It is worth mentioning that the peak at $285.1 \mathrm{eV}(\mathrm{C}-\mathrm{C} / \mathrm{C}-\mathrm{H}$ groups in PES phenyl rings) does not appear in RGO coated fabrics. Therefore, the XPS results really correspond to the graphene layers 
(surface analysis) and not to polyester substrate. The first peak at $284.4 \mathrm{eV}$ was attributed to sp2 carbon in the graphitic network. The peak at $285.9 \mathrm{eV}$ was due to C$\mathrm{OH}$ groups. The peak at $287.0 \mathrm{eV}$ was ascribed to $\mathrm{C}=\mathrm{O}$ and $\mathrm{C}-\mathrm{O}-\mathrm{C}$ (epoxy sp3 carbon bonds on the basal plane) groups. The peak at $289.0 \mathrm{eV}$ was ascribed to $\mathrm{O}=\mathrm{C}-\mathrm{OH}$ groups [30]. The assignments for RGO coated fabrics with 1, 2, 3 and 4 RGO layers are shown in Table 1. In addition, GO coated PES textile was also analyzed. There were not significant differences between binding energies for the different samples. However in the case of the PES-GO sample, the bands attributed to oxidized species had higher intensity (compared to the sp2 carbon band) than these of the samples coated with RGO. This result can be observed in Fig. 2-b where the C1s spectrum of the different samples is compared. If we compare the bands around $285.9,287.0$ and $289.0 \mathrm{eV}$, it can be seen that the intensity of these bands (compared to the sp2 carbon band) is higher for the PES-GO sample than for the RGO coated samples. The diminution of the oxidized bands in RGO coated fabrics arises from the reduction of oxygen produced during the chemical reduction by sodium dithionite. Oxygen is removed from the structure and the partial restoration of the $\mathrm{sp}^{2}$ graphitic network is produced. The restoration is not complete and functional groups remain in the RGO layers [18]. The $\mathrm{sp}^{2}$ fraction (obtained dividing the $\mathrm{sp}^{2}$ carbon content by the total carbon content) increases from 0.54 for PES-GO to $0.66-0.69$ for the different RGO coated samples. This increase of the $\mathrm{sp}^{2}$ fraction produces an increment of the conductivity [31, 32].

The analysis of the O1s high resolution XPS spectrum for the PES-1G sample showed two peaks at 531.5 and $533.2 \mathrm{eV}$ (figure not shown). The first peak was ascribed to $\mathrm{O}=\mathrm{C}$ groups, and the second peak was attributed to $\mathrm{O}-\mathrm{C}$ groups [29]. The $\mathrm{O} 1 \mathrm{~s} / \mathrm{C} 1 \mathrm{~s}$ ratio gives an indication of the oxygen content. For the PES-GO sample was 0.40 and it was reduced to $0.20-0.26$ for the RGO coated samples. This parameter with the $\mathrm{sp}^{2}$ fraction 
gives a clear indication of the reduction of the oxygen content and the partial restoration of the $\mathrm{sp}^{2}$ structure.

\subsection{Electrochemical impedance spectroscopy (EIS)}

\subsubsection{Metal/sample/metal symmetrical configuration}

Electrochemical impedance spectroscopy was employed to characterize electrically the different samples obtained. The electrical resistance $(\Omega)$, as well as the phase angle $\left(^{\circ}\right)$ was obtained by means of EIS measurements. The latter parameter gives an indication of the insulating (capacitor) or conducting (resistor) nature of the sample analyzed. The sample was located between two metallic conductors (stainless steel and mercury) and the measurements were performed. Fig. 3 shows the Bode plots for the different samples analyzed. In Fig 3-a, the impedance modulus $(|\mathrm{Z}|)$ is represented versus the measuring frequencies $(\mathrm{Hz})$. First of all, PES fabric was characterized to measure its $(|\mathrm{Z}|)$, as it can be seen it is higher than $10^{11} \Omega$ for low frequencies. In Fig. 3-b, the phase angle is represented versus the measuring frequencies $(\mathrm{Hz})$. The phase angle obtained for PES was $90^{\circ}$, data for low frequencies is not represented since noise caused by the high values of $|\mathrm{Z}|$ was observed. This value indicates that polyester behaves like an insulating material with capacitative behavior. When GO was deposited on PES, there was no significant variation of $|\mathrm{Z}|$ and phase angle, the values obtained were $4.4 \cdot 10^{10}$ (at $0.01 \mathrm{~Hz}$ ) and $90^{\circ}$, respectively. GO is also an insulating material due to the disrupted $\mathrm{sp}^{2}$ structure [31]. However, when GO was reduced in the PES-1G sample, there was a decrease of $|\mathrm{Z}|$ to $10^{5} \Omega$, more than five orders of magnitude. Changes in the phase angle were also observed, approaching to $0^{\circ}$ at low frequencies. This indicates a resistive behavior, typical of conducting materials. These results are in accordance with XPS measurements that shown the removal of oxygen and the partial restoration of the 
$\mathrm{sp}^{2}$ structure. This produces an increase in the conductivity [31, 32]. When more RGO coatings were applied, $|\mathrm{Z}|$ diminished progressively to $19450 \Omega, 2157 \Omega$ and $667 \Omega$; for PES-2G, PES-3G and PES-4G, respectively (values measured at $0.01 \mathrm{~Hz}$ ). For these samples, the phase angle was $0^{\circ}$ in the entire frequency range, indicating a perfect conductive behavior. The increasing number of coatings produces a decrease of $|\mathrm{Z}|$ due to the higher RGO content that produces a better contact between the RGO sheets and hence a better conductivity. The values of sheet resistance, conductivity or resistance obtained in bibliography by other authors have been: Yu et al [21] deposited directly graphene sheets on polyester fabrics and obtained around $700 \Omega$ /square after 35 cycles of dipping in a solution containing graphene sheets. The sheet resistance with only 10 dipping cycles was more than $10^{6} \Omega$ /square. Fugetsu et al. [22] reported resistance values ranging from $10^{2}$ to $10^{9} \Omega / \mathrm{cm}$ depending on the RGO content for the deposition of RGO on polyarylate. Gu et al. [23] obtained resistances of $2.01 \cdot 10^{7} \Omega$ for one coating process of RGO on cotton fabrics. The necessity of more coating processes to achieve low resistances in the case of employing graphene sheets [21] could be explained by the low adhesion of graphene on polyester fabrics due to the low presence of polar groups on graphene sheets. This is why the employment of graphene oxide with polar groups is a best way to produce RGO coated conducting fabrics.

\subsubsection{Metal/sample/electrolyte asymmetrical configuration}

A standard three-electrode design was employed to measure the EIS response of PESGO and PES-RGO samples in $0.1 \mathrm{M} \mathrm{H}_{2} \mathrm{SO}_{4}$. It is important to note that the substrate of the electrodes was polyester. Polyester is an insulator material, therefore any contribution can be expected from the substrate. The EIS response will be due only to GO and RGO material deposited on polyester. 
Two different equivalent circuits were used to fit the experimental data for PES-GO and PES-RGO samples [33]. Fig. 4-a shows the equivalent circuit used for fitting the PESGO sample. This electric circuit is composed by:

- Rs: Electrolyte resistance

- Rct: Ion-electron charge transfer resistance at the graphene (surface without oxygencontaining functional groups)/solution interface.

- Cdl: Double-layer capacitance in parallel associated with Rct.

- Ws: Finite-length Warburg diffusion for transmissive boundary conditions. This element represents the counter-ion diffusion through the oxidized graphene structure. W-R: Diffusion resistance. W-T: $1^{2} / \mathrm{D}(\mathrm{s})$, 1: length of the diffusion layer, D: diffusion coefficient. W-P: Warburg exponent.

- Cd: Capacitance due to the oxidized graphene structure.

Fig. 4-b shows the equivalent circuit for the PES-RGO samples, where the different elements have the following meanings:

- Rs: Electrolyte resistance

- Rct: Ion-electron charge transfer resistance at the $\mathrm{RGO} /$ solution interface.

- Cdl: Double-layer capacitance in parallel associated with Rct.

- W-semi-infinite: Warburg impedance for semi-infinite linear diffusion. $\sigma$ : Warburg diffusion coefficient $\left(\Omega \cdot \mathrm{cm}^{2} \cdot \mathrm{s}^{-1 / 2}\right)$.

The Nyquist plot for a PES-GO sample and a PES-1G one is shown in Fig. 5. The experimental data and fitting results obtained by the equivalent circuits are shown in 
table 2. Two different behaviours were shown in the Nyquist plots. At low frequencies, the PES-GO sample $(\square)$ presented transmissive finite-length Warburg diffusion. The counter-ions diffuse through an oxidized graphene structure with finite thickness. The Nyquist plot for the PES-1G sample (o) showed a semi-infinite linear diffusion. In the PES-1G sample, the quantity of oxidized compounds is minor. The behaviour of the PES-1G sample is mainly as a compact graphene coating. Therefore, this "ideal" electrode acts as a planar electrode with semi-infinite linear diffusion.

In table 2, the fitting data for the ion-electron charge transfer resistance at the interfaces (Rct) for PES-GO and PES-RGO samples are shown. The PES-1G sample showed a decrease of Ret in comparison with the PES-GO one. In addition, all the RGO samples presented lesser Rct than PES-GO sample. The best result (the best electrocatalytic behaviour) was for the PES-4G sample.

The Warburg diffusion coefficient is also shown in table 2 for RGO samples with semiinfinite diffusion. The minor Warburg diffusion coefficient value was obtained for the PES-4G sample. The diffusion coefficient was one order of magnitude lower for the PES-4G sample in comparison with the PES-1G one, with only 1 RGO coating.

To compare the entire electric response for PES-GO and PES-RGO samples, Fig. 6 shows the impedance modulus $|\mathrm{Z}|$ versus frequency plot between 10 and $0.01 \mathrm{~Hz}$. The highest value at the lowest frequency was 13367 for the GO sample. The data for PESRGO samples were always lower than the $|\mathrm{Z}|$ for the PES-GO specimen. The $|\mathrm{Z}|$ for the PES-4G sample was more than one order of magnitude lower in comparison with the PES-GO one. The electric response, due mainly to diffusion processes for all the specimens, was very fast for the PES-4G specimen in comparison with the PES-GO one. In addition, the $|\mathrm{Z}|$ due mainly to diffusion processes decreased when more RGO coatings were applied. 


\subsection{Scanning electrochemical microscopy (SECM).}

The electroactivity of the different RGO coated samples was tested by means of the SECM approach curves. To record these curves, the ultramicroelectrode (UME) is polarized at a potential at which the redox processes at the UME tip occur at a diffusion controlled rate. The measured current is defined as $i_{\infty}=4 n F D C a$, where $n$ is the number of electrons, $\mathrm{F}$ the Faraday constant, D the diffusion coefficient, $\mathrm{C}$ is the bulk concentration of the redox mediator and a is the radius of the UME tip.

In this work, two types of redox mediators were employed:

1) $\mathrm{Ru}\left(\mathrm{NH}_{3}\right)_{6}{ }^{3+}(\mathrm{Ox})$ was reduced to $\mathrm{Ru}\left(\mathrm{NH}_{3}\right)_{6}{ }^{2+}$ (Red) at the UME tip at a potential of $-0.4 \mathrm{~V}$ (vs. $\mathrm{Ag} / \mathrm{AgCl} 3 \mathrm{M} \mathrm{KCl})$.

2) $\mathrm{Fe}(\mathrm{CN})_{6}^{3-}(\mathrm{Ox})$ was reduced to $\mathrm{Fe}(\mathrm{CN})_{6}^{4-}$ (Red) at the UME tip at a potential of $0 \mathrm{~V}$ (vs. Ag/AgCl $3 \mathrm{M} \mathrm{KCl).}$

$\mathrm{Fe}(\mathrm{CN})_{6}{ }^{4-}(\mathrm{Red})$ was oxidized to $\mathrm{Fe}(\mathrm{CN})_{6}{ }^{3-}(\mathrm{Ox})$ at the UME tip at a potential of $+0.4 \mathrm{~V}$ (vs. $\mathrm{Ag} / \mathrm{AgCl} 3 \mathrm{M} \mathrm{KCl})$.

Depending on the electroactivity of the samples (substrates) to study and the distance between the UME and the substrate, different situations can occur:

- When the UME is sufficiently far from the substrate there is no modification of the diffusion current. In this case the UME tip current is $i_{\infty}$.

- If the substrate is non conductive, when the ultramicroelectrode (UME) approaches the substrate there is a hindrance to the diffusion of electroactive species. This situation creates a tip current decrease, $\mathrm{i}<\mathrm{i}_{\infty}$. This situation is known as negative feedback [34].

- On the other hand, if the electrode is conductive, when the electrode approaches the surface, there is an increment of the reactive species flux $(\mathrm{Ox})$ since the 
surface potential is able to regenerate the mediator. This causes an increase of the current measured at the UME tip, $\mathrm{i}>\mathrm{i}_{\infty}$. This case is known as positive feedback [34].

In approach curves, the normalized current registered at the UME (I) is represented vs. the normalized distance (L). The normalized current is defined as follows: $I=i / i_{\infty}$ where "i" is the current measured at the UME tip and $i_{\infty}$ is the diffusion current defined above. The normalized currents depend on $R G(R G=R g / a$, where $R g$ is the radius of the insulating glass surrounding the Pt tip of radius "a") and the normalized distance L; where $\mathrm{L}=\mathrm{d} / \mathrm{a}$ ( $\mathrm{d}$ is the UME-substrate separation). The RG of the UME tip employed in this work was $R G \geq 20$. According to Rajendran el al. [35], Pade's approximation gives a close and simple equation with less relative error for all distances and valid for RG $>$ 10. The approximate expression of the steady-state normalized current assuming positive feedback for finite conductive substrate together with finite insulating glass thickness is:

$$
I_{T}{ }^{C}=\left[\frac{1+1.5647 / L^{+1.316855} / L^{2}+0.4919707 / L^{3}}{1+1.1234 / L^{+0.626395 / L^{2}}}\right]_{(1)}
$$

The expression for the normalized current assuming negative feedback was based on the equation obtained by Bard et al., for a $R G=20$ and $L$ range 0.4-20 [36]:

$$
I_{T}{ }^{I N S}=\left[\frac{1}{0.3554+2.0259 / L+0.62832 \times \exp (-2.55622 / L)}\right]_{(2)}
$$

Theoretical approach curves obtained for positive and negative feedback models were obtained according to equations 1 and 2 to compare the experimental data with the theoretical models.

Fig. 7 shows the different electroactivity of PES surface coated with GO or RGO. Fig. 7-a shows the lack of electroactivity of polyester substrate (discontinuous line) since 
negative feedback was obtained. When GO was deposited on polyester the electroactivity was not substantially changed as it can be observed in this figure. Three approach curves were obtained in different locations of the fabric and similar negative feedback curves were obtained. The results obtained almost followed the theoretical negative feedback model also shown in Fig. 7-a. In Fig. 7-b the approach curves for fabrics coated with different number of RGO layers are shown. As it can be seen in all of them, positive feedback was obtained, indicating the electroactivity of the fabrics. PES-1G showed the lowest positive feedback with values around 1.1 . When 2,3 or 4 layers of RGO were applied to the fabric, its electroactivity increased notably as observed in approach curves, where positive feedback values around 1.6-1.7 were obtained. Similar values of positive feedback have been obtained in bibliography for CVD deposited graphene [37]. This increase of electroactivity could be related to a better coverage of the surface of the fabric. In this case only the degree of coverage of the fabrics has influence on the electrochemical response since the samples were analyzed at its open circuit potential (OCP).

Fig. 8 shows different approach curves obtained with the $\mathrm{Fe}(\mathrm{CN})_{6}{ }^{3-/ 4-}$ redox mediator for the PES-4G sample in different locations of the fabric. In Fig. 8-a the sample acts as a reductant and in Fig. 8-b the sample acts as an oxidant. As it can be seen in this figure, similar values of positive feedback were obtained for both cases, indicating that the fabric can either act as an oxidant or a reductant with equal values of heterogeneous electron charge transfer kinetics.

Another redox mediator was employed to compare the results obtained with the $\mathrm{Fe}(\mathrm{CN})_{6}^{3-/ 4-}$ one. Fig. 9 shows the electroactivity of the different RGO coated samples using the $\mathrm{Ru}\left(\mathrm{NH}_{3}\right)_{6}{ }^{3+/ 2+}$ redox couple. As it can be seen the values of electroactivity slightly increased with the number of RGO layers. For the PES-1G sample the value of 
positive feedback was around 1.3 and for the PES-4G sample was around 1.4. There was little difference between the different samples. If this result is compared with that obtained for the $\mathrm{Fe}(\mathrm{CN})_{6}^{3-/ 4}$ mediator, lower normalized current values are obtained for the $\mathrm{Ru}\left(\mathrm{NH}_{3}\right)_{6}{ }^{3+/ 2+}$ redox couple. A possible explanation for this result would be given by the fact that $\mathrm{Fe}(\mathrm{CN})_{6}{ }^{3-/ 4-}$ is sensitive to the state of the carbon surface while $\mathrm{Ru}\left(\mathrm{NH}_{3}\right)_{6}{ }^{3+/ 2+}$ represents the simplest case of an outer-sphere electron transfer with no known chemical interactions with the surface [38]. Taking into account these results, the best redox mediator for analyzing the surface of these samples would be the $\mathrm{Fe}(\mathrm{CN})_{6}^{3-/ 4-}$ one.

One main application of SECM technique is the scanning of surfaces to obtain 2D and $3 \mathrm{D}$ images of the electrochemical activity $[34,37]$. To obtain these representations the surface of the sample is scanned at a constant height inside the influence of the substrate (in our case we employed an initial height of $70 \mu \mathrm{m}$ above the sample). Fig. 10 shows the $2 \mathrm{D}$ and 3D SECM images obtained for the PES-4G sample with the $\mathrm{Fe}(\mathrm{CN})_{6}{ }^{3 / 4-}$ couple. In this case the sample acts as a reductant. According to the results obtained, two conclusions can be made. Since the normalized current is I $>1$ on the whole fabric, a homogeneous coating of RGO was obtained on the PES surface. On the other hand, the different degrees of positive feedback obtained are due to the topography of the textile substrate (warp and weft) which modifies the UME-surface distance. The peaks and valleys coincide exactly with the topography of the fabric (Fig. 1-d).

\section{Conclusions}

A homogeneous coating of reduced graphene oxide (RGO) was obtained on polyester fabrics by applying different RGO layers. It was difficult to observe the RGO sheets 
deposited on the fabrics by scanning electron microscopy. Only in some zones they could be spotted, taking advantage of the folds created when they were adsorbed on the surface of polyester fibres. XPS measurements showed the diminution of the $\mathrm{O} 1 \mathrm{~s} / \mathrm{C} 1 \mathrm{~s}$ ratio and the increase of the $\mathrm{sp}^{2}$ fraction, which give a clear indication of the reduction of the oxygen content and the partial restoration of the $\mathrm{sp}^{2}$ structure when GO was reduced to RGO. Electrical measurements performed by electrochemical impedance spectroscopy showed the change in the electrical properties when GO was reduced to RGO. The resistance in metal/sample/metal symmetrical configuration decreased more than 5 orders of magnitude when one layer of GO was reduced. Phase angle also changed form $90^{\circ}$ (capacitative behavior) to $0^{\circ}$ (conductive behavior). The application of several RGO coatings produced a progressive diminution of the resistance due to the higher RGO content. EIS measurements in metal/sample/electrolyte asymmetrical configuration showed better electrocatalytic behaviour and faster diffusion rate for RGO specimens. Scanning electrochemical microscopy (SECM) showed the influence of the redox mediator on the electroactivity measured. With the $\mathrm{Fe}(\mathrm{CN})_{6}{ }^{3-/ 4-}$ redox mediator, higher values of positive feedback than that obtained for the $\mathrm{Ru}\left(\mathrm{NH}_{3}\right)_{6}{ }^{3+/ 2+}$ redox pair were observed. The explanation for this fact is that $\mathrm{Ru}\left(\mathrm{NH}_{3}\right)_{6}{ }^{3+/ 2+}$ is an outer-sphere electron transfer with no chemical interactions with the surface. On the other hand $\mathrm{Fe}(\mathrm{CN})_{6}{ }^{3-/ 4-}$ is sensitive to the oxidation state of the carbon surface. The results obtained also showed that the fabrics could also act as an oxidant or a reductant with equal heterogeneous transfer heterogeneous electron charge transfer kinetics in both cases.

\section{Acknowledgements}


Authors thank to the Spanish Ministerio de Ciencia e Innovación (contract CTM201123583) and Universitat Politècnica de València (Vicerrectorado de Investigación PAID06-10 contract 003-233) for the financial support. J. Molina is grateful to the Conselleria d'Educació (Generalitat Valenciana) for the FPI fellowship. A.I. del Río is grateful to the Spanish Ministerio de Ciencia y Tecnología for the FPI fellowship. J.C. Galván is gratefully acknowledged for help with EIS measurements and data analysis.

\section{References}

[1] F. Salaün, E. Devaux, S. Bourbigot, P. Rumeau, Thermoregulating response of cotton fabric containing microencapsulated phase change materials, Thermochim Acta 506 (2010) 82-93.

[2] W. Wu, C.Q. Yang, Comparison of different reactive organophosphorus flame retardant agents for cotton. Part II: Fabric flame resistant performance and physical properties, Polym. Degrad. Stabil. 92 (2007) 363-369.

[3] X. Jiang, X. Tian, J. Gu, D. Huang, Y. Yang, Cotton fabric coated with nano TiO2acrylate copolymer for photocatalytic self-cleaning by in-situ suspension polymerization, Appl. Surf. Sci. 257 (2011) 8451-8456.

[4] R.F. Service, Electronic textiles charge ahead, Science 301 (2003) 909-911.

[5] D. Akbarov, B. Baymuratov, P. Westbroek, R. Akbarov, K. Declerck, P. Kiekens, Development of electroconductive polyacrylonitrile fibers through chemical metallization and galvanization, J. Appl. Electrochem. 36 (2006) 411-418.

[6] A. Bhattacharyya, M. Joshi, Development of polyurethane based conducting nanocomposite fibers via twin screw extrusion, Fiber. Polym. 12 (2011) 734-740. 
[7] A. Kaynak, S.S. Najar, R.C. Foitzik, Conducting nylon, cotton and wool yarns by continuous vapor polymerization of pyrrole, Synth. Met. 158 (2008) 1-5.

[8] J. Molina, A.I. del Río, J. Bonastre, F. Cases, Chemical and electrochemical polymerisation of pyrrole on polyester textiles in presence of phosphotungstic acid, Eur. Polym. J. 44 (2008) 2087-98.

[9] J. Molina, M.F. Esteves, J. Fernández, J. Bonastre, F. Cases, Polyaniline coated conducting fabrics. Chemical and electrochemical characterization, Eur. Polym. J. 47 (2011) 2003-2015.

[10] K.S. Novoselov, A.K. Geim, S.V. Morozov, D. Jiang, Y. Zhang, S.V. Dubonos, I.V. Grigorieva, A.A. Firsov, Electric field effect in atomically thin carbon films, Science 306 (2004) 666-669.

[11] A.K. Geim, K.S. Novoselov, The rise of graphene, Nat. Mater. 6 (2007) 183-191.

[12] A.K. Geim, Graphene: status and prospects, Science 324 (2009) 1530-1534.

[13] A.H. Castro Neto, F. Guinea, N.M.R. Peres, K.S. Novoselov, A.K. Geim, The electronic properties of graphene, Rev. Mod. Phys. 81 (2009) 109-162.

[14] H.B. Heersche, P. Jarillo-Herrero, J.B. Oostinga, L.M.K. Vandersypen, A.F. Morpurgo, Bipolar supercurrent in graphene, Nature 446 (2007) 56-59.

[15] M.J. Allen, V.C. Tung, R.B. Kaner, Honeycomb carbon: A review of graphene, Chem. Rev. 110 (2010) 132-145.

[16] C. Soldano, A. Mahmood, E. Dujardin, Production, properties and potential of graphene, Carbon 48 (2010) 2127-2150.

[17] V. Singh, D. Joung, L. Zhai, S. Das, S.I. Khondaker, S. Seal, Graphene based materials: Past, present and future, Prog. Mater. Sci. 56 (2011) 1178-1271.

[18] S. Park, R.S. Ruoff, Chemical methods for the production of graphenes, Nat Nanotechnol 4 (2009) 217-224. 
[19] S. Stankovich, D.A. Dikin, G.H.B. Dommett, K.M. Kohlhaas, E.J. Zimney, E.A.

Stach, R.D. Piner, S.T. Nguyen, R.S. Ruoff, Graphene-based composite materials, Nature 440 (2006) 282-286.

[20] R. Verdejo, M.M. Bernal, L.J. Romasanta, M.A. Lopez-Manchado, Graphene filled polymer nanocomposites, J. Mater. Chem. 21 (2011) 3301-3310.

[21] G. Yu, L. Hu, M. Vosgueritchian, H. Wang, X. Xie, J.R. McDonough, X. Cui, Y. Cui, Z. Bao, Solution-processed graphene $/ \mathrm{MnO}_{2}$ nanostructured textiles for highperformance electrochemical capacitors, Nano Lett. 11 (2011) 2905-2911.

[22] B. Fugetsu, E. Sano, H. Yu, K. Mori, T. Tanaka, Graphene oxide as dyestuffs for the creation of electrically conductive fabrics, Carbon 48 (2010) 3340-3345.

[23] W. Gu, Y. Zhao, Graphene modified cotton textiles, Adv. Mat. Res. 331 (2011) 93-96.

[24] R.M. Souto, J.J. Santana, L. Fernández-Mérida, S. González, Sensing electrochemical activity in polymer coated metals during the early stages of coating degradation-Effect of the polarization of the substrate, Electrochim. Acta 56 (2011) 9596-9601.

[25] M.V. Mirkin, B.R. Horrocks, Electroanalytical measurements using the scanning electrochemical microscope, Anal. Chim. Acta 406 (2000) 119-146.

[26] J. Bonastre, J. Molina, A.I. del Río, J.C. Galván, F. Cases, Study of the electrical properties of novel hybrid organic-inorganic conducting textiles of polypyrrolephosphotungstatepolyester using electrochemical impedance spectroscopy, Synth. Met. 161 (2011) 1958-1965.

[27] Complete textile glossary, available from:

http://www.celaneseacetate.com/textile glossary filament acetate.pdf, 2001. Last accessed 15th November 2012. 
[28] T. Zhou, F. Chen, K. Liu, H. Deng, Q. Zhang, J. Feng, Q. Fu, A simple and efficient method to prepare graphene by reduction of graphite oxide with sodium hydrosulfite, Nanotechnology 22 (2011) 045704.

[29] M. Kormunda, J. Pavlik, Characterization of oxygen and argon ion flux interaction with PET surfaces by in-situ XPS and ex-situ FTIR, Polym. Degrad. Stabil. 95 (2010) $1783-1788$.

[30] D. Yang, A. Velamakanni, G. Bozoklu, S. Park, M. Stoller, R.D. Piner, S. Stankovich, I. Jung, D.A. Field, C.A. Ventrice Jr., R.S. Ruoff, Chemical analysis of graphene oxide films after heat and chemical treatments by X-ray photoelectron and Micro-Raman spectroscopy, Carbon 47 (2009) 145-152.

[31] D.R. Dreyer, S. Park, C.W. Bielawski, R.S. Ruoff, The chemistry of graphene oxide, Chem. Soc. Rev. 39 (2010) 228-240.

[32] D. Chen, H. Feng, J. Li, Graphene oxide: preparation, functionalization, and electrochemical applications, Chem. Rev. 112 (2012) 6027-6053.

[33] E. Casero, A.M. Parra-Alfambra, M.D. Petit-Domínguez, F. Pariente, E. Lorenzo, C. Alonso, Differentiation between graphene oxide and reduced graphene by electrochemical impedance spectroscopy (EIS), Electrochem. Commun. 20 (2012) 6366.

[34] P. Sun, F.O. Laforge, M.V. Mirkin, Scanning electrochemical microscopy in the 21st century, Phys. Chem. Chem. Phys. 9 (2007) 802-823.

[35] L. Rajendran, S.P. Ananthi, Analysis of positive feedback currents at the scanning electrochemical microscope, J. Electroanal. Chem. 561 (2004) 113-118.

[36] A.J. Bard, M.V. Mirkin, Scanning Electrochemical Microscopy, Marcel Dekker Inc., New York, 2001. 
[37] C. Tan, J. Rodríguez-López, J.J. Parks, N.L. Ritzert, D.C. Ralph, H.D. Abruña, Reactivity of monolayer chemical vapor deposited graphene imperfections studied using scanning electrochemical microscopy, ACS Nano 6 (2012) 3070-3079.

[38] R.L. McCreery, Advanced carbon electrode materials for molecular electrochemistry, Chem. Rev. 108 (2008) 2646-2687.

\section{Figure captions}

Fig. 1. Micrographs of: (a) PES-1G x10000; (b) PES-1G x10000; (c) PES-4G x500; (d) PES-4G x100.

Fig. 2. High resolution C1s XPS core level spectrum for: a) PES-1G, b) PES, PES-GO, PES-1G, PES-2G, PES-3G and PES-4G samples.

Fig. 3. Bode plots for PES, PES-GO, PES-1G, PES-2G, PES-3G and PES-4G. Sample located between two metallic conductors. Frequency range from $10^{5} \mathrm{~Hz}$ to $10^{-2} \mathrm{~Hz}$.

Fig. 4. Equivalent circuits for: a) PES-GO sample, b) PES-RGO samples.

Fig. 5. Nyquist plots of a PES-GO sample ( $\square$ ) and a PES-1G one in $0.1 \mathrm{M} \mathrm{H}_{2} \mathrm{SO}_{4}$. Exposed electrode area: $0.28 \mathrm{~cm}^{2}$. Frequency range from $10^{4}$ to $10^{-2} \mathrm{~Hz}$. (-) Fitting of experimental data. 
Fig. 6. Impedance modulus $|\mathrm{Z}|$ vs. frequency plot for PES-GO ( $\Delta)$, PES-1G ( $\square)$, PES-2G $(\diamond)$, PES-3G (*) and PES-4G (o) samples in $0.1 \mathrm{M} \mathrm{H}_{2} \mathrm{SO}_{4}$. Exposed electrode area: 0.28 $\mathrm{cm}^{2}$. Frequency range from 10 to $10^{-2} \mathrm{~Hz}$.

Fig. 7. Approaching curves for: a) PES (- - -), PES-GO (continuous lines) and theoretical negative feedback model (口). b) PES-1G, PES-2G, PES-3G, PES-4G. Theoretical positive feedback model is also presented for comparison $(\Delta)$. Obtained with a $100 \mu \mathrm{m}$ diameter Pt tip in $0.01 \mathrm{M} \mathrm{Fe}(\mathrm{CN})_{6}{ }^{3-}$ and $0.1 \mathrm{M} \mathrm{KCl}$. The tip potential was $0 \mathrm{mV}$ (vs $\mathrm{Ag} / \mathrm{AgCl}$ ) and the approach rate was $10 \mu \mathrm{m} \mathrm{s}^{-1}$.

Fig. 8. Approaching curves for PES-4G (continuous lines), obtained with a $100 \mu \mathrm{m}$ diameter Pt tip in $0.01 \mathrm{M} \mathrm{Fe}(\mathrm{CN})_{6}{ }^{3-} / 0.01 \mathrm{M} \mathrm{Fe}(\mathrm{CN})_{6}{ }^{4-}$ and $0.1 \mathrm{M} \mathrm{KCl}$, the approach rate was $10 \mu \mathrm{m} \mathrm{s}^{-1}$. a) tip potential $+400 \mathrm{mV}$, b) tip potential $0 \mathrm{mV}$. Theoretical positive feedback model is also presented for comparison $(\Delta)$.

Fig. 9. Approaching curves for: a) PES-1G, PES-2G, PES-3G, PES-4G. Theoretical positive feedback model is also presented for comparison $(\Delta)$. b) PES-4G (continuous lines) and theoretical positive feedback model $(\Delta)$. Obtained with a $100 \mu \mathrm{m}$ diameter $\mathrm{Pt}$ tip in $0.01 \mathrm{M} \mathrm{Ru}\left(\mathrm{NH}_{3}\right)_{6}{ }^{3+}$ and $0.1 \mathrm{M} \mathrm{KCl}$. The tip potential was $-400 \mathrm{mV}$ (vs $\mathrm{Ag} / \mathrm{AgCl}$ ) and the approach rate was $10 \mu \mathrm{m} \mathrm{s}^{-1}$.

Fig. 10. 3D (a) and 2D (b) constant height SECM images of: PES-4G sample. $0.25 \mathrm{~cm}^{2}$ geometrical area sample, images were taken with a $100 \mu \mathrm{m}$ diameter Pt tip, in $0.01 \mathrm{M}$ $\mathrm{Fe}(\mathrm{CN})_{6}{ }^{4-}$ and $0.1 \mathrm{M} \mathrm{KCl}$ at a constant height. The tip potential was $+400 \mathrm{mV}$, the scan 
rate was $200 \mu \mathrm{m} \mathrm{s}^{-1}$ in comb mode; lengths of $\mathrm{x}$ and y lines were $1500 \mathrm{x} 1500 \mu \mathrm{m}$ with increments of $50 \mu \mathrm{m}$.

\section{Table captions}

Table 1. C1s and O1s assignments for the XPS analyses of different RGO and GO coated fabrics.

Table 2. Results of the fitting of impedance data of PES-GO and PES-RGO samples in $0.1 \mathrm{M} \mathrm{H}_{2} \mathrm{SO}_{4}$. Data obtained by the equivalent circuits shown in Fig. 4. 


\section{Highlights:}

- Graphene-coated fabrics have been obtained by chemical reduction of graphene oxide.

- XPS measurements showed the partial restoration of the $\mathrm{sp}^{2}$ structure of graphene.

- Electrochemical impedance spectroscopy showed the conductive behaviour of fabrics.

- Better electrocatalytic properties were obtained in EIS measurements in solutions.

- Scanning electrochemical microscopy showed also the increase of electroactivity. 

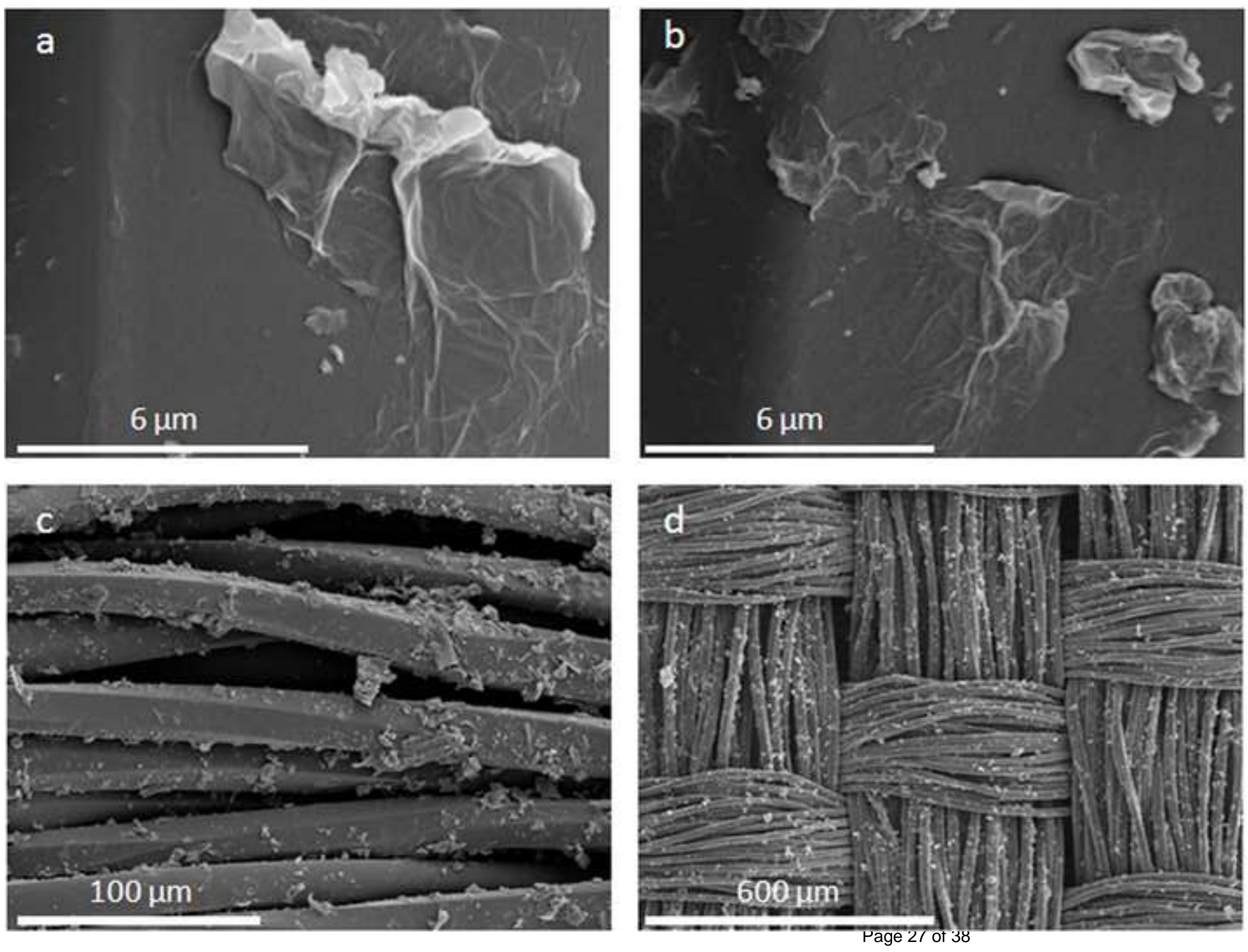

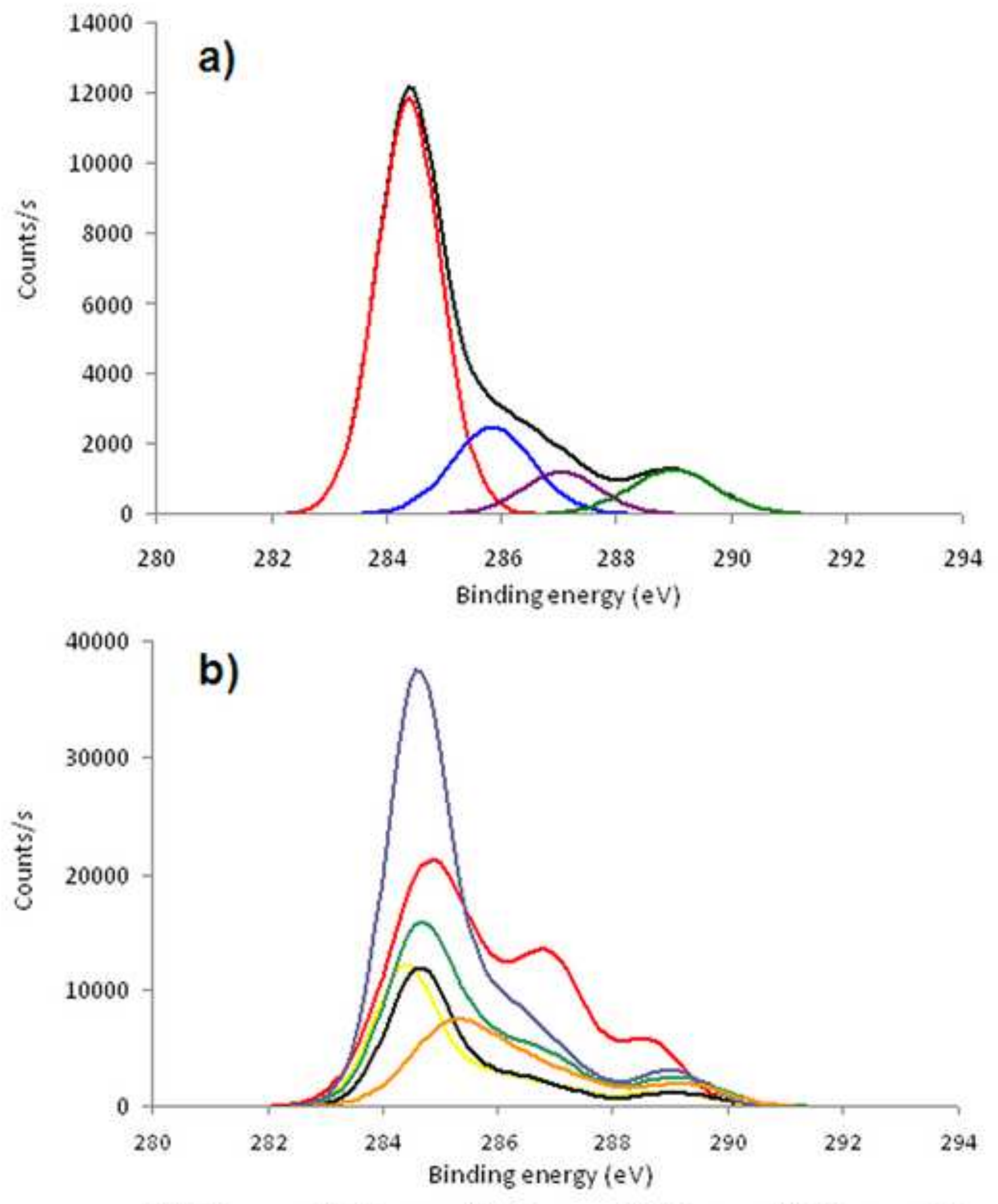

- PES-GO

PES-16 PES-2G

-PES-3G PES-4G PES 
a) $10^{12}$

$$
\begin{aligned}
& 10^{10} \\
& 10^{8} \\
& \frac{\mathrm{E}}{\text { 을 }} 10^{5} \\
& \frac{\mathrm{N}}{\mathrm{N}} 10^{4} \\
& 10^{2} \\
& 10^{\circ}
\end{aligned}
$$

00000

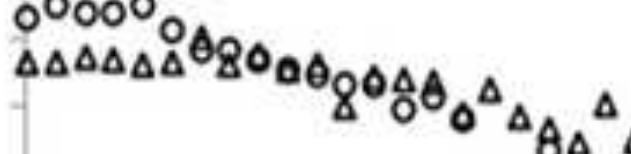

$0_{0} 0_{0} \Delta \Delta_{0}^{\Delta} \Delta$

00000000000000000000000000000000080 00000000000000000000000000000000000008888888888888

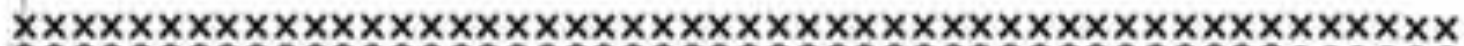
00000000000000000000000000000000000000000000000000

$10^{2}$

$10^{-2}$

\section{$10^{-1}$}

$10^{\circ}$

$10^{1}$

$10^{2}$

$10^{3}$

$10^{4}$

$10^{5}$

b)

120

100

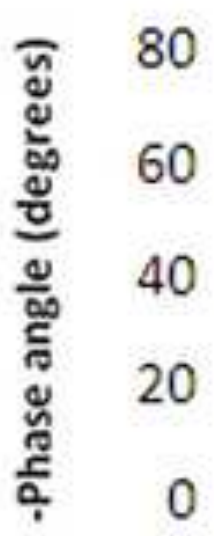

๑

$10^{-2}$

$10^{-1}$

$10^{\circ}$

$10^{1}$

$10^{2}$

$10^{3}$

$10^{4}$

$10^{5}$

Frequency $(\mathrm{Hz})$
OPES
$\triangle$ PES-GO
D PES-1G
$\triangle$ PES-2G
X. PES-3G
O PES-4G 

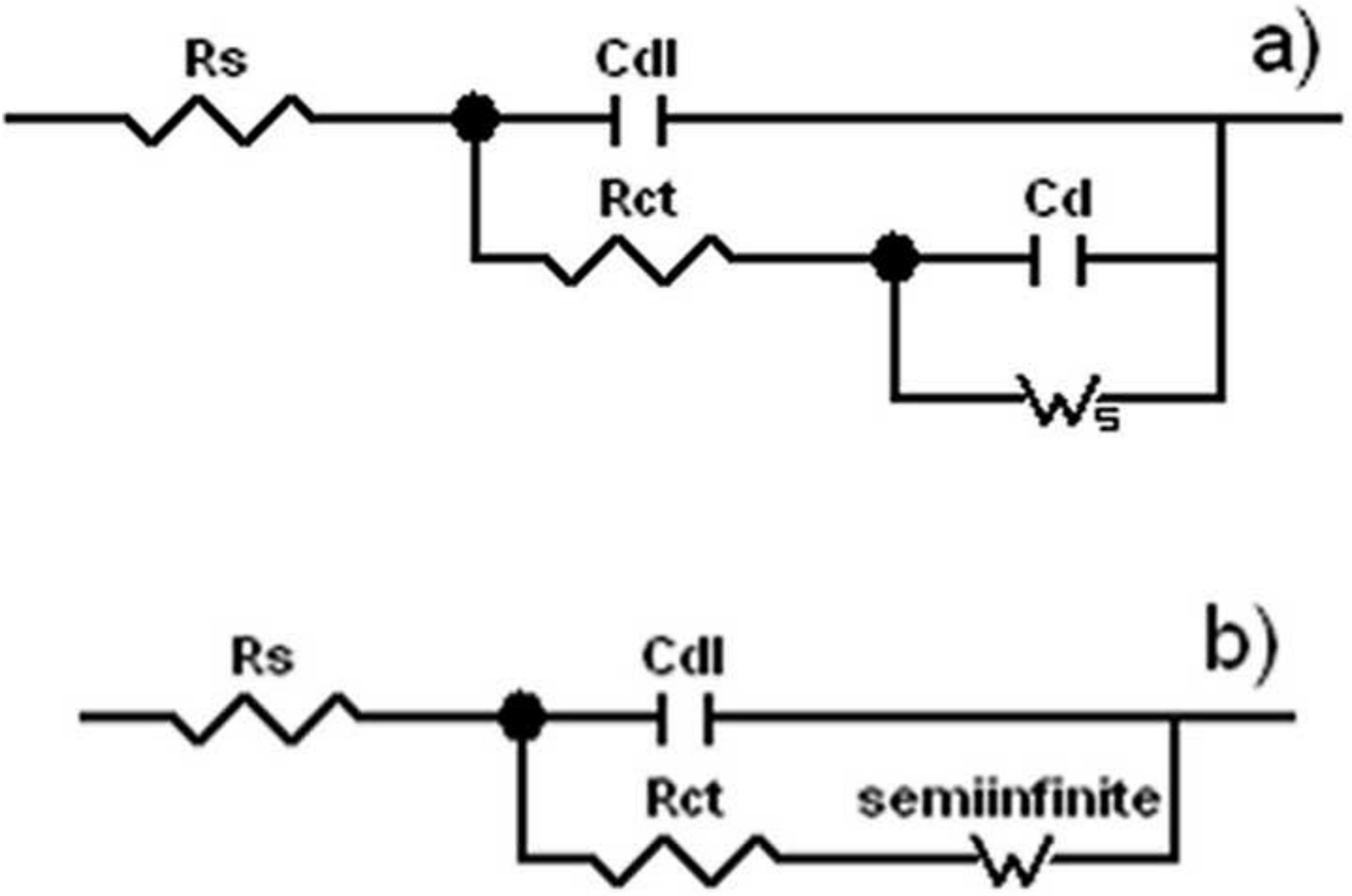

Page 30 of 38 
Figure(5)

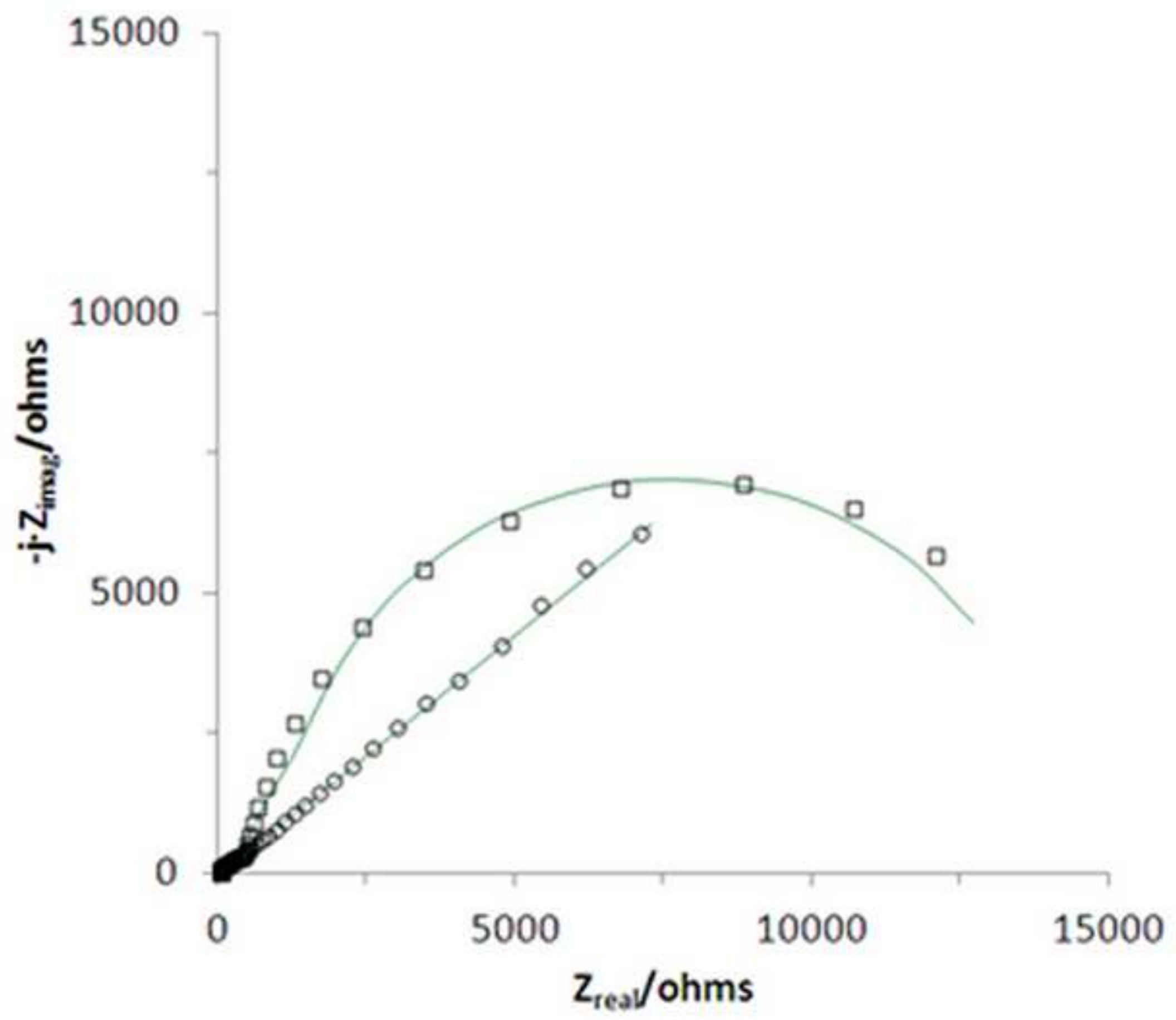

rage 31 о 38 


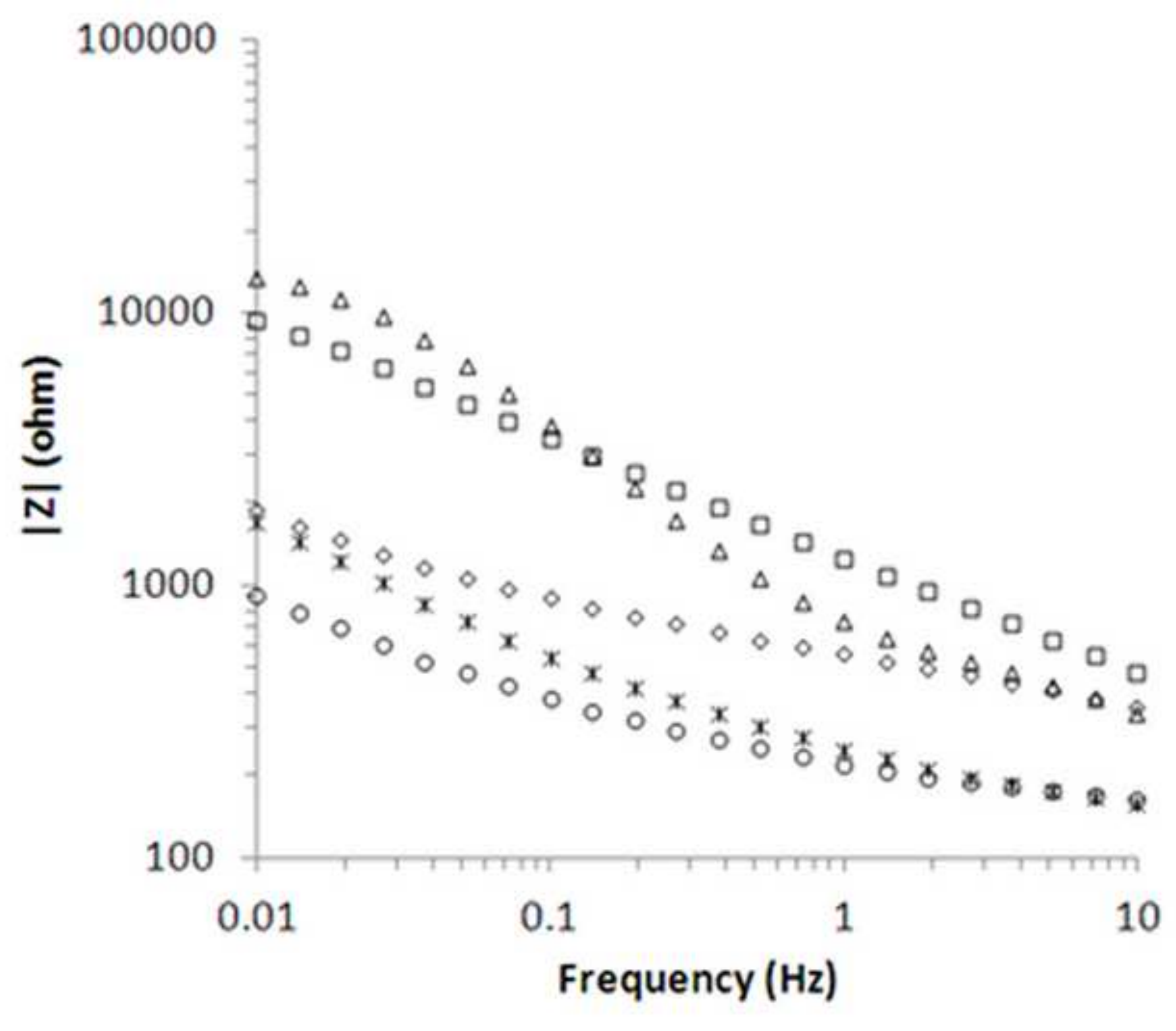

rage $3<$ or 38

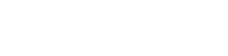

(2)

(

(2)

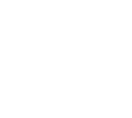

\begin{abstract}
Figure
\end{abstract}


a)

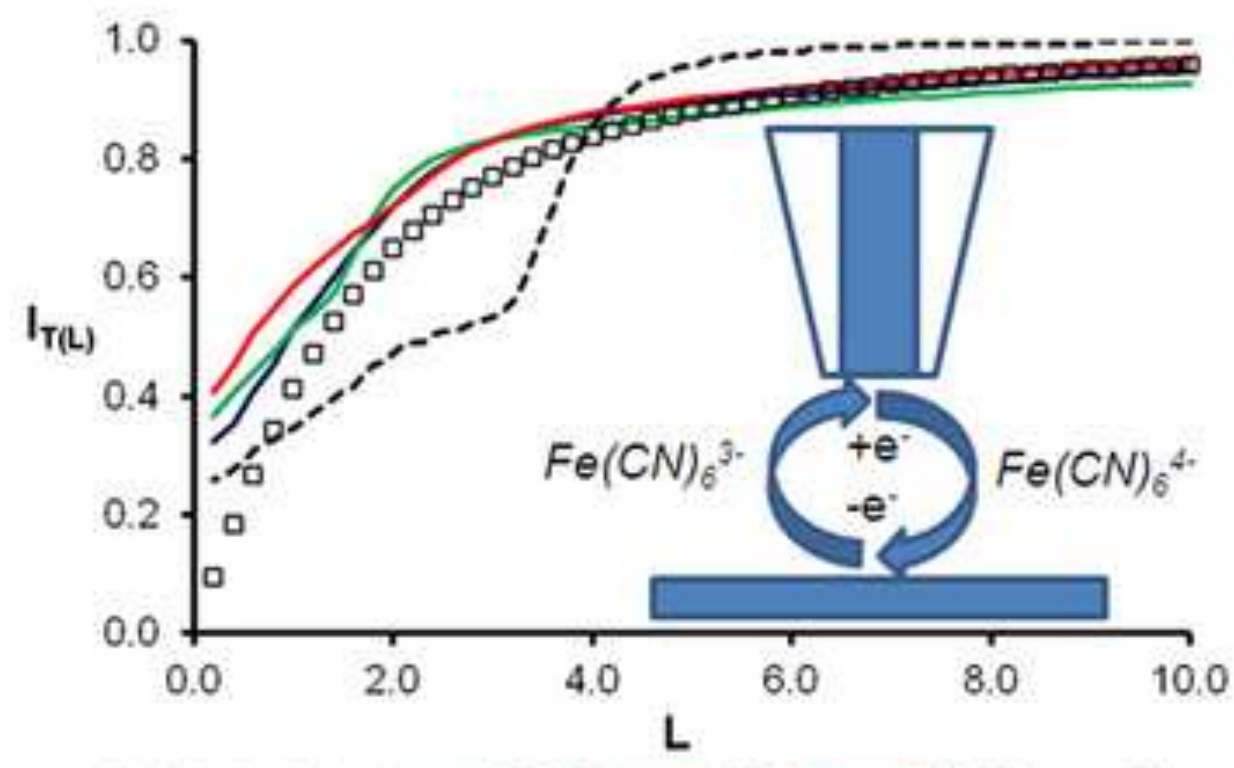

a Negotive foedbock

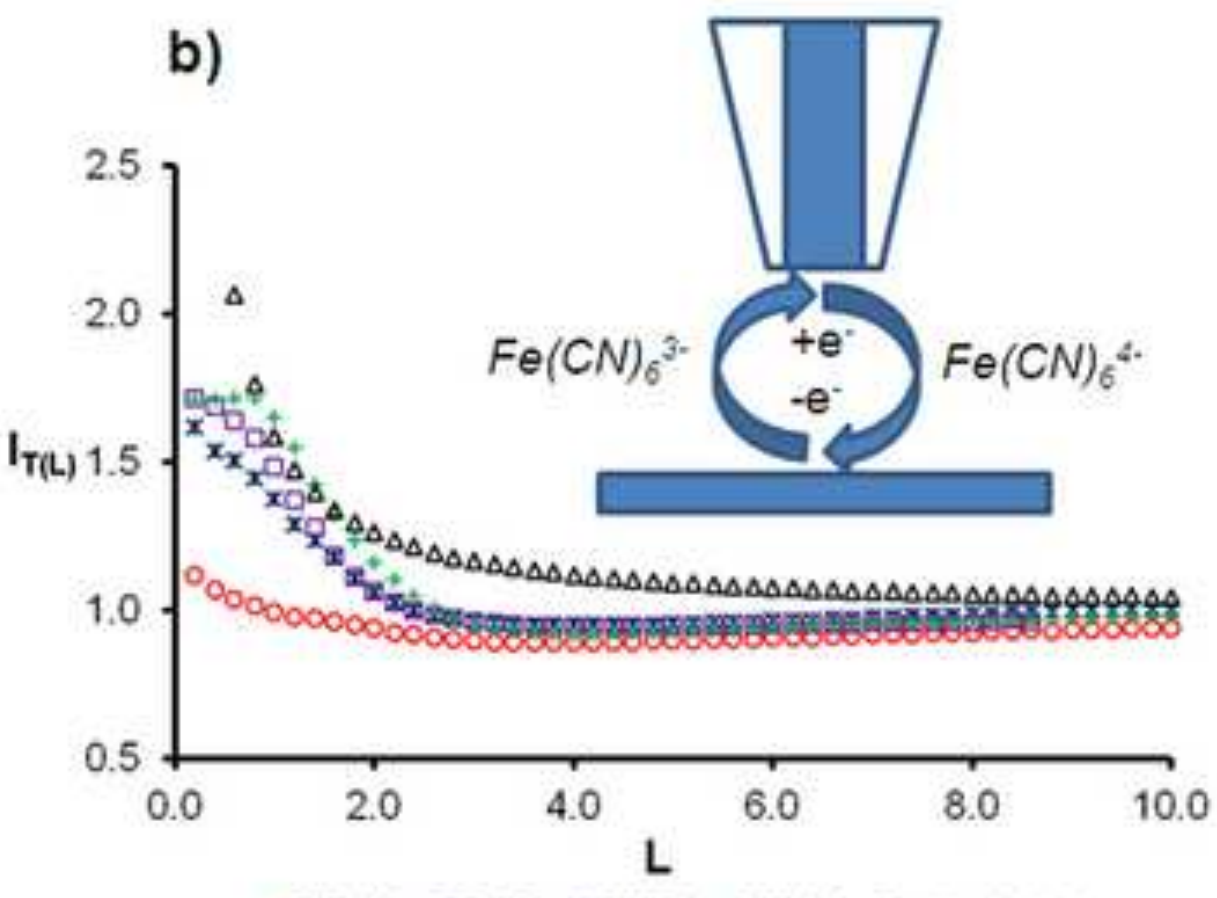

OPES-1G xPES-2G aPES-3G +PES-4G APOAtwoteodosck 


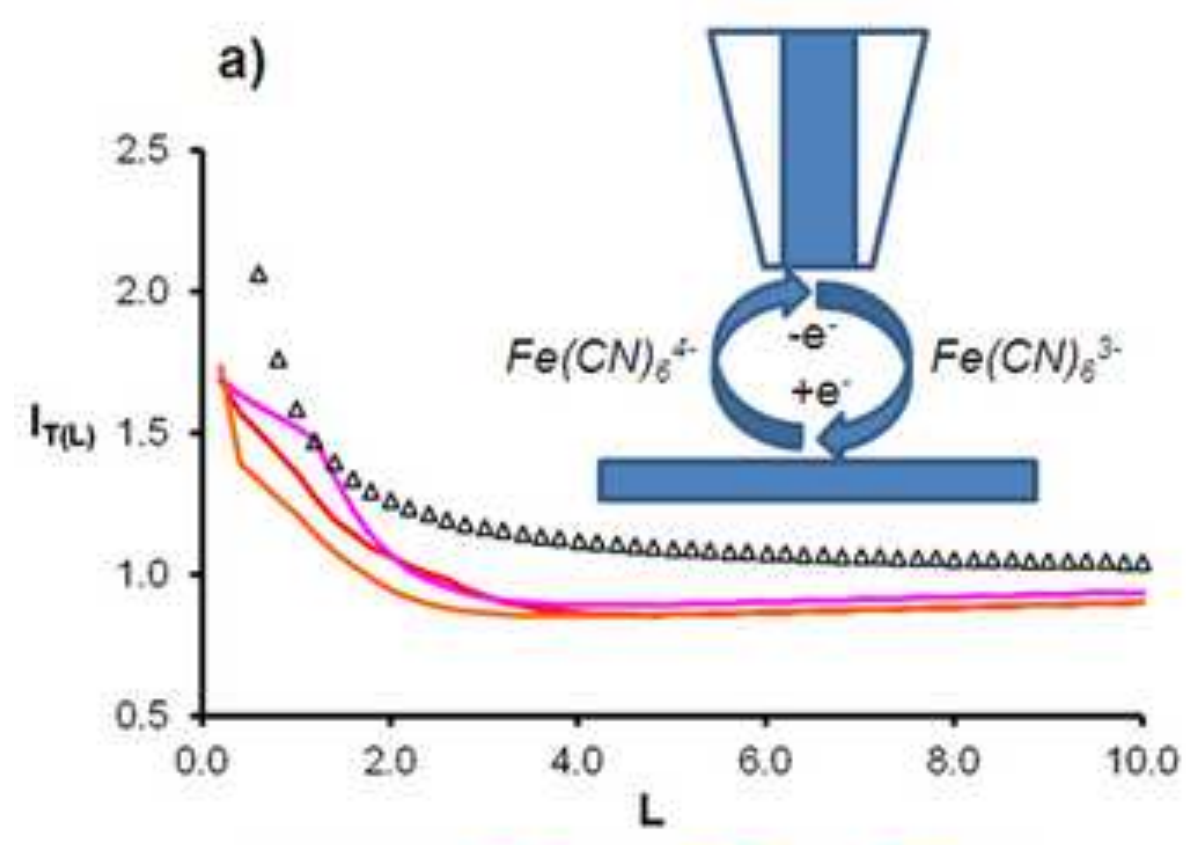

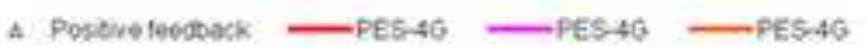

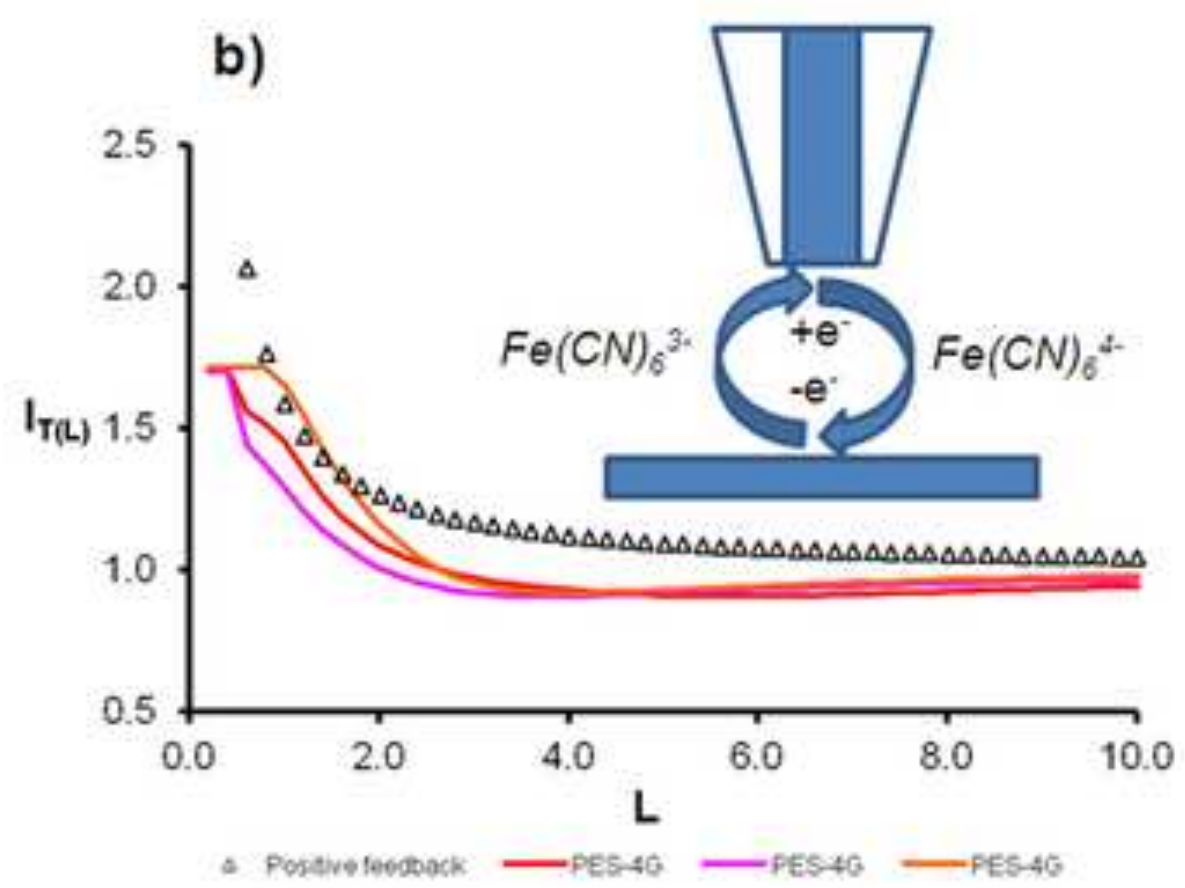

Page 34 of 38 


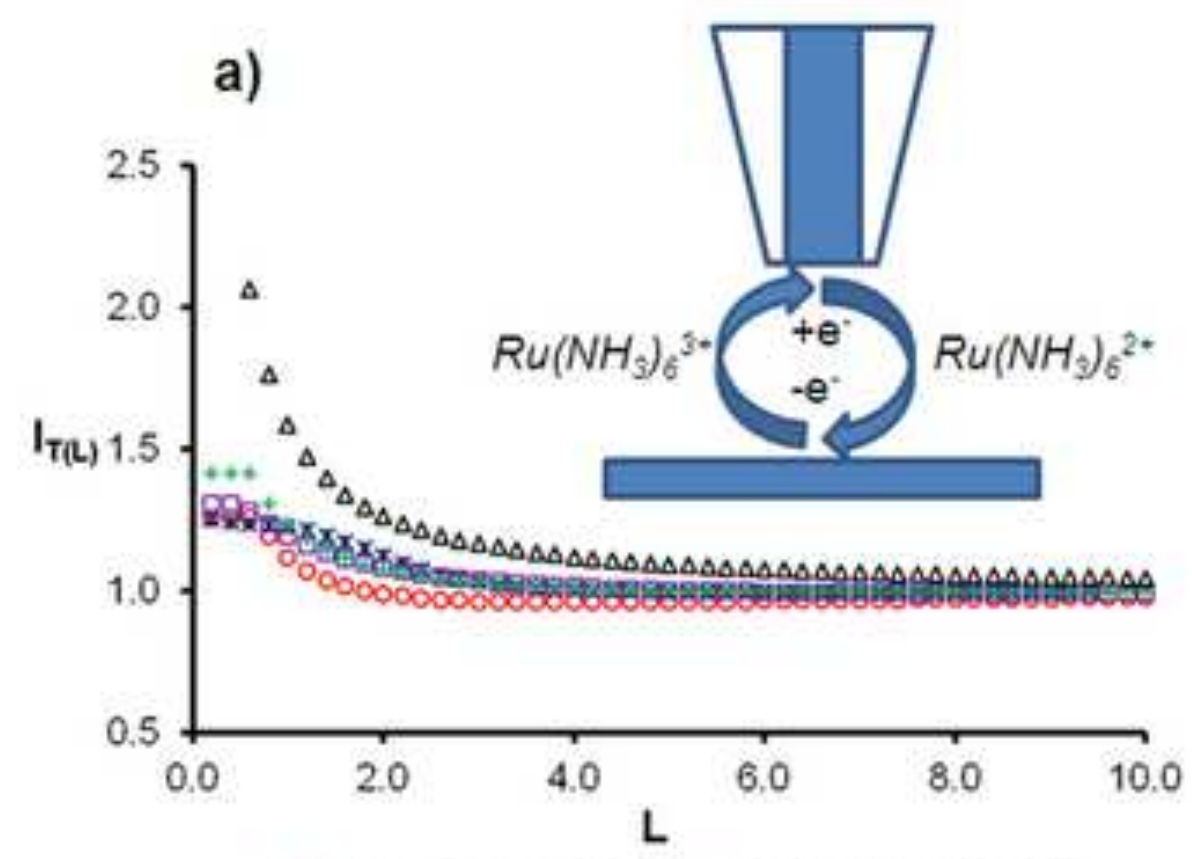

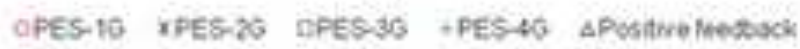

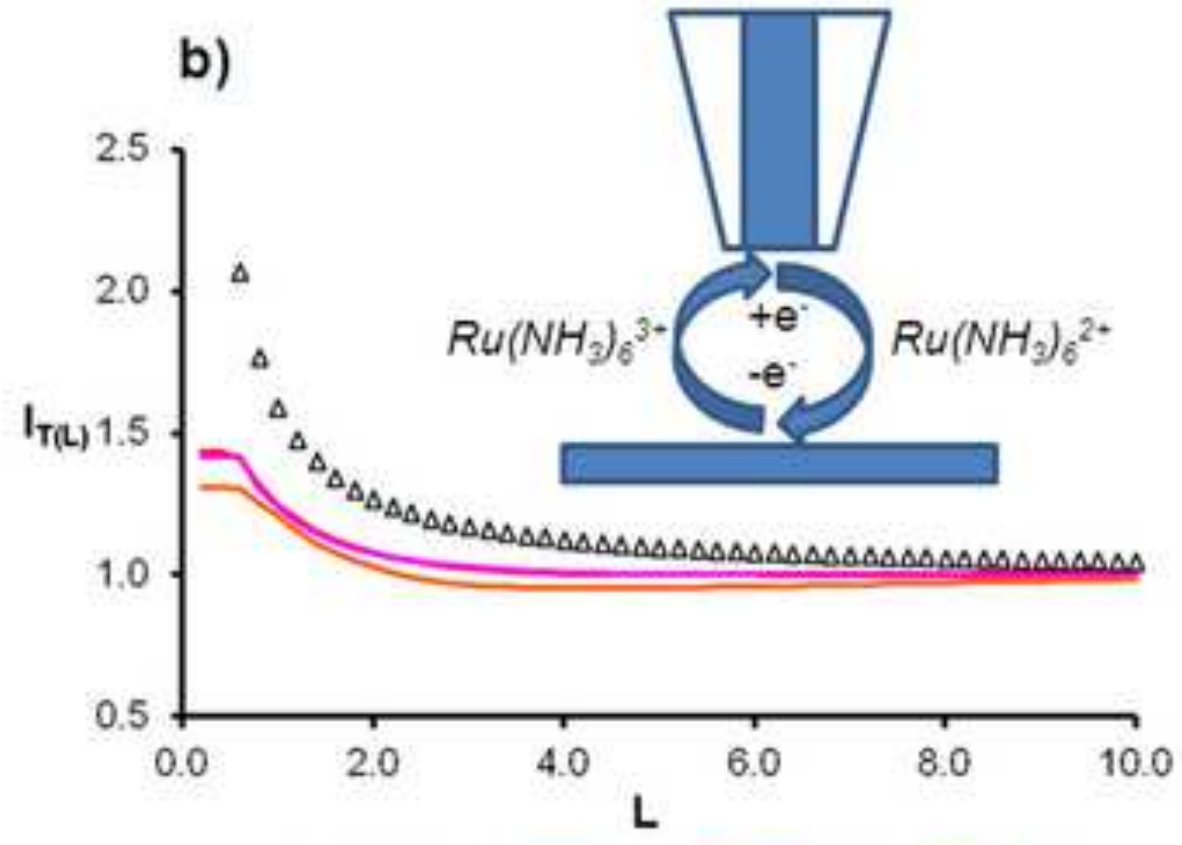

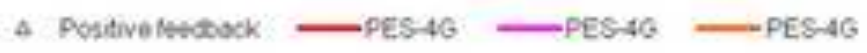


Figure(10)

a)

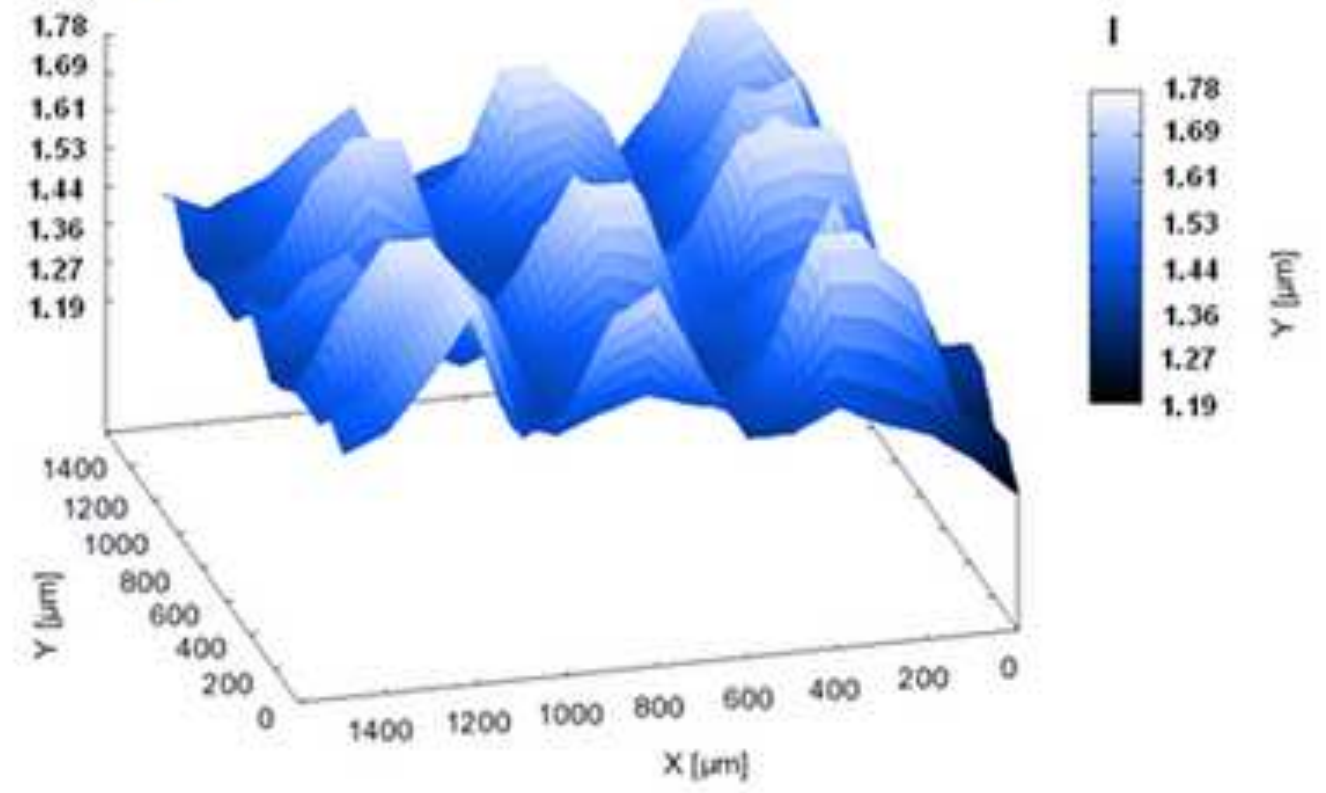

b)

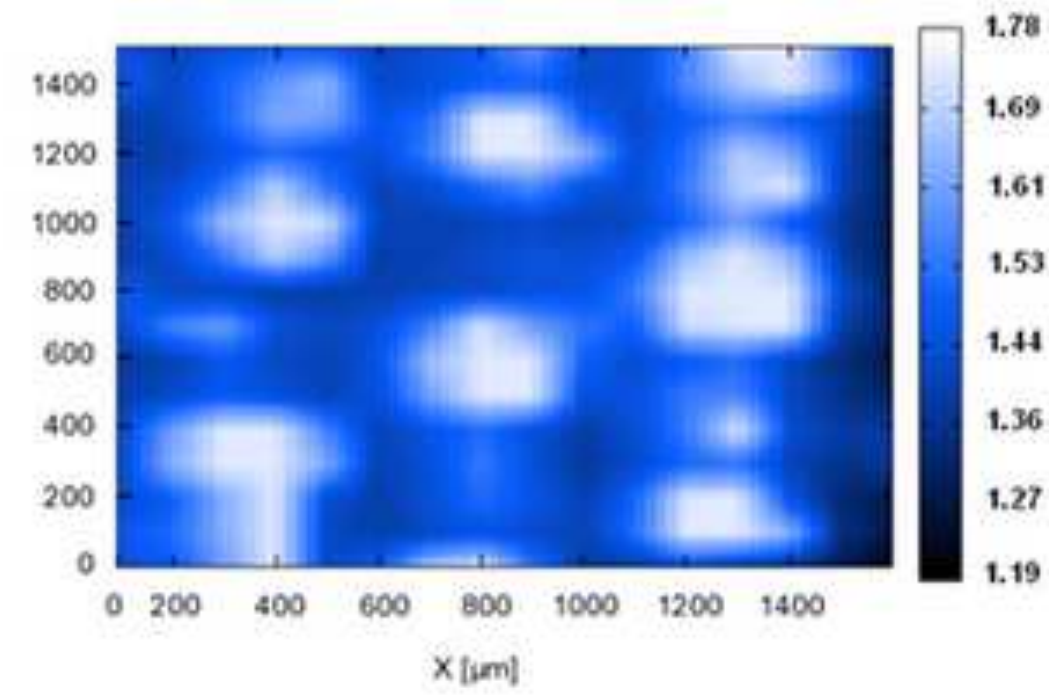




\begin{tabular}{cccccc}
\hline \multicolumn{7}{c}{ C1s } \\
\hline PES-1G & PES-2G & PES-3G & PES-4G & PES-GO & Assignments \\
\hline 284.4 & 284.6 & 284.6 & 284.6 & 284.8 & sp $^{2}$ carbon \\
285.9 & 286.1 & 285.8 & 286.1 & 285.8 & C-OH \\
287.0 & 287.0 & 286.9 & 287.1 & 286.9 & C=O and C-O-C \\
289.0 & 289.1 & 289.1 & 289.0 & 288.7 & O=C-OH \\
\hline \multicolumn{7}{c}{ O1s } \\
\hline PES-1G & PES-2G & PES-3G & PES-4G & PES-GO & Assignments \\
\hline 531.5 & 531.9 & 532.0 & 532.2 & 531.8 & O=C \\
533.2 & 533.5 & 533.6 & 533.6 & 533.0 & O-C \\
\hline \multicolumn{7}{c}{ O1s C1s atomicratio } \\
\hline RGO 1 layer & RGO 2 layers & RGO 3 layers & RGO 4layers & GO 1layer \\
\hline 0.20 & 0.24 & 0.26 & 0.20 \\
\hline \multicolumn{7}{c}{0.40} \\
\hline
\end{tabular}




\begin{tabular}{|c|c|c|c|c|c|}
\hline & PES-GO & PES-1G & PES-2G & PES-3G & PES-4G \\
\hline $\operatorname{Rs}(\Omega)$ & 47 & 44 & 76 & 38 & 80 \\
\hline $\operatorname{Rct}(\Omega)$ & 329 & 136 & 201 & 86 & 63 \\
\hline $\mathrm{Cdl}(\mathrm{F})$ & $1.9 \cdot 10^{-5}$ & $1.0 \cdot 10^{-5}$ & $1.4 \cdot 10^{-3}$ & $1.9 \cdot 10^{-3}$ & $1.3 \cdot 10^{-4}$ \\
\hline $\mathrm{Cd}(\mathrm{F})$ & $15.5 \cdot 10^{-5}$ & - & - & - & - \\
\hline Ws-R $(\Omega)$ & 13602 & - & - & - & - \\
\hline Ws-T (s) & 10.2 & - & - & - & - \\
\hline Ws-P & 0.55 & - & - & - & - \\
\hline$\sigma\left(\Omega \cdot \mathrm{cm}^{2} \cdot \mathrm{s}^{-1 / 2}\right)$ & - & 439 & $\$ 2$ & $\$ 9$ & 44 \\
\hline $\mathrm{Z}$ at $0.01 \mathrm{~Hz}(\Omega)$ & 13367 & 9364 & 1889 & 1704 & 915 \\
\hline
\end{tabular}

